\title{
Características produtivas do trigo em função de fontes e doses de nitrogênio ${ }^{1}$
}

\author{
Andre Mateus Prando ${ }^{2}$, Claudemir Zucareli ${ }^{2}$, \\ Vanoli Fronza ${ }^{3}$, Fábio Álvares de Oliveira ${ }^{4}$, Adilson Oliveira Júnior ${ }^{4}$
}

\begin{abstract}
Productive characteristics of wheat according to nitrogen sources and levels

Nitrogen fertilization is an important management practice in grasses and quite complex, due to several factors which influence it, such as climatic conditions, cropping systems and available levels and sources. This study aimed at evaluating the effect of topdressing nitrogen $(\mathrm{N})$ sources and levels on the productive characteristics of wheat (Triticum aestivum L.) grown after soybean, under no-till system. The experiment was conducted in an Oxisol, in Londrina, Paraná State, Brazil. The experimental design was randomized blocks, in a $3 \times 4$ factorial scheme, with four replications. As topdressing N sources, urea, urea + urease inhibitor (NBPT) and polymer-coated urea were evaluated, in 2008, and urea, urea + urease inhibitor (NBPT) and ammonium sulfate, in 2009 , in four doses $\left(0.0 \mathrm{~kg} \mathrm{ha}^{-1}\right.$, $40.0 \mathrm{~kg} \mathrm{ha}^{-1}, 80.0 \mathrm{~kg} \mathrm{ha}^{-1}$ and $120.0 \mathrm{~kg} \mathrm{ha}^{-1}$ of N) applied 20 days after emergence. Plant height, lodging percentage, mass of 1,000 grains, grain yield and hectoliter mass were determined, and results showed that increased topdressing $\mathrm{N}$ levels promoted plants lodging, decreasing the mass of 1,000 grains, yield and hectoliter mass. The N sources did not affect the yield of the BRS Pardela cultivar grown after soybean.
\end{abstract}

KEY-WORDS: Triticum aestivum L.; urease inhibitor (NBPT); polymer-coated urea; nitrogen fertilization; lodging.

\section{INTRODUÇÃO}

O desenvolvimento e a crescente utilização de cultivares de trigo com porte reduzido, maior tolerância ao acamamento e alto potencial produtivo têm implicado no uso mais frequente de insumos (Zagonel et al. 2002, Fornasieri Filho 2008). Para se alcançar altas produtividades e viabilizar a exploração da

\section{RESUMO}

A adubação nitrogenada é uma importante prática de manejo em gramíneas e bastante complexa, em função dos diversos fatores que a influenciam, como condições climáticas, sistemas de cultivo, doses e fontes disponíveis. Este trabalho objetivou avaliar o efeito de fontes e doses de nitrogênio $(\mathrm{N})$ em cobertura sobre as características produtivas do trigo (Triticum aestivum L.) cultivado em sistema de semeadura direta, em sucessão à cultura da soja. O experimento foi realizado utilizando-se Latossolo Vermelho distroférrico, em Londrina (PR). O delineamento experimental utilizado foi o de blocos casualizados, em esquema fatorial $3 \times 4$, com quatro repetições. Como fontes de $\mathrm{N}$ na adubação de cobertura, foram avaliados a ureia, ureia + inibidor de urease (NBPT) e ureia revestida com polímeros, em 2008, e ureia, ureia + inibidor de urease (NBPT) e sulfato de amônio, em 2009, em quatro doses $\left(0,0 \mathrm{~kg} \mathrm{ha}^{-1}, 40,0 \mathrm{~kg} \mathrm{ha}^{-1}, 80,0 \mathrm{~kg} \mathrm{ha}^{-1} \mathrm{e}\right.$ $120,0 \mathrm{~kg} \mathrm{ha}^{-1} \mathrm{de} \mathrm{N}$ ) aplicadas 20 dias após a emergência das plantas. Foram avaliados a altura de plantas, percentagem de acamamento, massa de 1.000 grãos, rendimento de grãos e massa do hectolitro, e os resultados mostraram que o incremento nas doses de $\mathrm{N}$ em cobertura favoreceu o acamamento de plantas, proporcionando redução na massa de 1.000 grãos, na produtividade e na massa do hectolitro. As fontes de $\mathrm{N}$ não afetaram o desempenho produtivo da cultivar BRS Pardela, cultivada após a soja.

PALAVRAS-CHAVE: Triticum aestivum L.; inibidor de urease (NBPT); ureia revestida com polímero; adubação nitrogenada; acamamento.

cultura do trigo, a fertilização do solo e a adequada nutrição da planta são indispensáveis. $\mathrm{O}$ nitrogênio (N) é o nutriente mais absorvido e o mais exportado pelas plantas de trigo. Além disto, exerce forte influência na definição da produtividade desta cultura.

No Estado do Paraná, a dose utilizada é recomendada em função da cultura anterior, no entanto, a quantidade de matéria orgânica, a expectativa de

1. Trabalho recebido em out./2012 e aceito para publicação em fev./2013 (n registro: PAT 20247).

2. Universidade Estadual de Londrina (UEL), Departamento de Agronomia, Londrina, PR, Brasil.

E-mails: andre.mateus@hotmail.com,claudemircca@uel.br.

3. Empresa de Pesquisa Agropecuária de Minas Gerais (Epamig), Fazenda Experimental Getúlio Vargas, Uberaba, MG, Brasil. E-mail: vanoli.fronza@embrapa.br.

4. Empresa Brasileira de Pesquisa Agropecuária (Embrapa Soja), Londrina, PR, Brasil.E-mails: fabio.alvares@embrapa.br, adilson.oliveira@embrapa.br. 
rendimento e a resistência da planta ao acamamento também devem ser consideradas. Doses menores de $\mathrm{N}$ limitam a produtividade, enquanto doses maiores podem levar ao acamamento de plantas, dificultando a colheita e reduzindo a produtividade (Zagonel et al. 2002).

Estudos avaliando a adubação nitrogenada são fundamentais para atualizar as recomendações técnicas e disponibilizar tecnologias que proporcionem produções economicamente satisfatórias. Zagonel et al. (2002), Trindade et al. (2006) e Teixeira Filho et al. (2007) observaram respostas positivas, para o aumento da produtividade, utilizando doses de $\mathrm{N}$ de até $70,0 \mathrm{~kg} \mathrm{ha}^{-1}$. No entanto, esta resposta pode ser alterada, devido ao tipo de cultura antecessora (soja ou milho), cultivar utilizada e condições climáticas.

A fonte mais utilizada no Brasil, para fornecimento de $\mathrm{N}$ às culturas, é a ureia. Do ponto de vista agrícola, a ureia tem, como vantagens, o elevado teor de $\mathrm{N}(45 \%)$, menor custo de transporte, alta solubilidade, menor corrosividade, compatibilidade com inúmeros fertilizantes e defensivos, pronta disponibilidade para as plantas e facilidade de manipulação, além de causar menor acidificação no solo, em relação a outros fertilizantes (Yano et al. 2005, Malavolta 2006). No entanto, possui, como característica desfavorável, elevadas perdas de $\mathrm{N}$ por volatilização, principalmente quando aplicado a lanço, na superfície, sendo que a perda de $\mathrm{N}$ será mais elevada quanto maior for a quantidade de palha e a falta de chuva para a sua incorporação (Golik et al. 2003, Cantarella et al. 2008).

As lavouras de trigo do Brasil são implantadas, em sua quase totalidade, na forma de plantio direto, resultando em benefícios como a conservação do solo e o aumento da produtividade. Porém, a cobertura vegetal presente na área, essencial para o sistema de plantio direto, reduz o contato da ureia com o solo, diminuindo a conversão do $\mathrm{NH}_{3} \mathrm{em} \mathrm{NH}_{4}^{+}$, reduzindo a adsorção de $\mathrm{NH}_{4}^{+}$aos coloides orgânicos e inorgânicos e facilitando, com isto, a volatilização de amônia (Cantarella et al. 2008).

A utilização de fertilizantes nitrogenados que promovem menores perdas de $\mathrm{N}-\mathrm{NH}_{3}$ é uma das estratégias para se aumentar a eficiência e reduzir a importação de fertilizantes, reduzir a poluição do ambiente e maximizar a produtividade do trigo. Atualmente, existem, no mercado, produtos à base de ureia, com aditivos que podem aumentar a sua eficiência. Como exemplos de aditivos, destacam-se o inibidor de urease $\mathrm{N}$-(n-butil) tiofosfórico triamida (NBPT) e o revestimento com polímeros.

O inibidor de urease (NBPT) ocupa o local de atuação da enzima urease e, com isto, atrasa a hidrólise da ureia e reduz o potencial de volatilização de $\mathrm{NH}_{3}$ na superfície do solo (Cantarella et al. 2008), enquanto o revestimento com polímeros consiste no recobrimento da superfície do grânulo de fertilizantes solúveis com uma barreira física semipermeável, que permite a solubilidade gradual do nutriente no solo (Pereira et al. 2009).

Cantarella et al. (2008) e Pereira et al. (2009) observaram redução na volatilização de amônia, com a utilização da ureia com inibidor de urease (NBPT) e da ureia revestida com polímeros. Contudo, Pereira et al. (2009) não observaram efeitos significativos no rendimento de grãos, assim como Prando et al. (2012a), nas características agronômicas, e Prando et al. (2012b), na qualidade fisiológica de sementes de trigo, quando compararam a ureia com a ureia com inibidor (NBPT) e ureia revestida com polímeros.

Estudos de campo são fundamentais para a validação dessas tecnologias, tanto para a comprovação da sua eficiência quanto para a definição das doses adequadas. Assim, este trabalho objetivou avaliar o efeito de fontes e doses de nitrogênio em adubação de cobertura, nas características produtivas do trigo (Triticum aestivum L.) cultivado em sistema de semeadura direta, em sucessão à cultura da soja.

\section{MATERIAL E MÉTODOS}

Dois experimentos foram realizados em condições de campo, durante os anos agrícolas de 2008 e 2009, no município de Londrina (PR) (23ำ $11^{\prime} \mathrm{S}, 51^{\circ} 10^{\prime} \mathrm{W}$ e $600 \mathrm{~m}$ de altitude). O solo da área experimental é classificado como Latossolo Vermelho distroférrico e o clima, segundo a classificação de Köppen, é Cfa.

Os experimentos foram realizados em duas áreas diferentes, ambas manejadas no sistema de semeadura direta, sobre palha de soja. $\mathrm{O}$ solo das áreas experimentais apresentava, na camada de $0,0-20,0 \mathrm{~cm}$, respectivamente em 2008 e 2009, as seguintes características: $\mathrm{pH}\left(\mathrm{CaCl}_{2}\right)$ : 4,6 e 5,5; C: 7,8 $\mathrm{g} \mathrm{dm}^{-3}$ e 7,11 $\mathrm{g} \mathrm{dm}^{-3}$; P (Mehlich-1): $6,2 \mathrm{mg} \mathrm{dm}^{-3}$ e $47,8 \mathrm{mg} \mathrm{dm}^{-3} ; \mathrm{H}+\mathrm{Al}: 4,0 \mathrm{cmol}_{\mathrm{c}} \mathrm{dm}^{-3} \mathrm{e}$ $3,3 \mathrm{cmol}_{\mathrm{c}} \mathrm{dm}^{-3} ; \mathrm{K}^{+}: 0,70 \mathrm{cmol}_{\mathrm{c}} \mathrm{dm}^{-3} \mathrm{e} 0,68 \mathrm{cmol}_{\mathrm{c}} \mathrm{dm}^{-3} ; \mathrm{Ca}^{2+}$ : $4,07 \mathrm{cmol}_{\mathrm{c}} \mathrm{dm}^{-3} \mathrm{e} 5,34 \mathrm{cmol}_{\mathrm{c}} \mathrm{dm}^{-3} ; \mathrm{Mg}^{2+}: 2,76 \mathrm{cmol}_{\mathrm{c}} \mathrm{dm}^{-3} \mathrm{e}$ $1,87 \mathrm{cmol}_{\mathrm{c}} \mathrm{dm}^{-3}$; CTC: $11,6 \mathrm{cmol}_{\mathrm{c}} \mathrm{dm}^{-3} \mathrm{e} 11,4 \mathrm{cmol}_{\mathrm{c}} \mathrm{dm}^{-3}$; saturação por bases (V\%): $65 \%$ e $71 \%$. Os dados climáticos de temperatura média diária e precipitação, durante o período de cultivo, foram obtidos junto à estação meteoro- 
lógica da Embrapa Soja, localizada a, aproximadamente, $1.000 \mathrm{~m}$ da área experimental.

O delineamento experimental utilizado foi o de blocos casualizados, em esquema fatorial $3 \times 4$, com quatro repetições, sendo o primeiro fator composto por fontes de $\mathrm{N}$ e o segundo por doses de $\mathrm{N}$, aplicadas em cobertura. Como fontes de $\mathrm{N}$ na adubação de cobertura, foram avaliadas a ureia, ureia + inibidor de urease (NBPT) e ureia revestida com polímeros, em 2008, e ureia, ureia + inibidor de urease (NBPT) e sulfato de amônio, em 2009, em quatro doses $\left(0,0 \mathrm{~kg} \mathrm{ha}^{-1}\right.$, $40,0 \mathrm{~kg} \mathrm{ha}^{-1}, 80,0 \mathrm{~kg} \mathrm{ha}^{-1}$ e $120,0 \mathrm{~kg} \mathrm{ha}^{-1}$ de N) aplicadas 20 dias após a emergência das plantas.

A ureia + inibidor de urease (NBPT) consiste em urea comercial, que contém $0,045 \%$ de aditivo NBPT [N-(n-butil) tiofosfórico triamida]. A ureia revestida com polímeros foi produzida pela própria empresa detentora da tecnologia, a qual utilizou os seguintes produtos comerciais, para o revestimento dos grânulos de ureia: KimCoat Poli N1 $\left(6,67 \mathrm{~L} \mathrm{t}^{-1}\right)$, KimCoat Poli N2 $\left(61,11 \mathrm{~kg} \mathrm{t}^{-1}\right)$ e KimCoat Poli N3 $\left(16,67 \mathrm{~kg} \mathrm{t}^{-1}\right)$, os quais foram adicionados, separadamente, sobre a ureia, em betoneira, para mistura e posterior ensaque, contendo $41,2 \%$ de $\mathrm{N}$, na sua composição.

As parcelas experimentais foram constituídas por 10 linhas, com 6,0 $\mathrm{m}$ de comprimento e espaçamento entre as linhas de $0,20 \mathrm{~m}$. Foram consideradas, como área útil de cada parcela experimental, as seis linhas centrais, desprezando-se $0,75 \mathrm{~m}$ nas extremidades, totalizando $5,4 \mathrm{~m}^{2}$ de área útil.

A adubação com nitrogênio, fósforo e potássio (NPK), na semeadura, foi realizada conforme os resultados da análise do solo, seguindo-se as indicações técnicas da Comissão Brasileira de Pesquisa de Trigo e Triticale para o Estado do Paraná (Fronza et al. 2008). Na adubação de semeadura, em 2008, foram distribuídos, no sulco de semeadura, $250 \mathrm{~kg} \mathrm{ha}^{-1} \mathrm{da}$ fórmula 08-20-20 e, em 2009, $300 \mathrm{~kg} \mathrm{ha}^{-1}$ da fórmula 08-28-16, correspondendo a $20 \mathrm{~kg} \mathrm{ha}^{-1}$ e $24 \mathrm{~kg} \mathrm{ha}^{-1}$ de $\mathrm{N}, 50 \mathrm{~kg} \mathrm{ha}^{-1}$ e $84 \mathrm{~kg} \mathrm{ha}^{-1}$ de $\mathrm{P}_{2} \mathrm{O}_{5}$ e $50 \mathrm{~kg} \mathrm{ha}^{-1} \mathrm{e}$ $48 \mathrm{~kg} \mathrm{ha}^{-1}$ de $\mathrm{K}_{2} \mathrm{O}$, respectivamente.

A cultivar utilizada foi a BRS Pardela, que possui ciclo médio (cerca de 60 a 70 dias da emergência ao espigamento), altura média de $79,0 \mathrm{~cm}$ e é moderadamente resistente ao acamamento, com boa capacidade de perfilhamento e elevado potencial produtivo, sendo indicada para solos de fertilidade média e alta.

As sementes foram tratadas com o fungicida triadimenol e o inseticida imidacloprid e as semeaduras realizadas em 24/04/2008 e 05/05/2009, visando à obtenção da densidade de, aproximadamente, 300 plantas $\mathrm{m}^{-2}$. A emergência de plântulas ocorreu seis dias após a semeadura, em ambos os experimentos.

A adubação de cobertura foi realizada aos 20 dias após a emergência, correspondendo ao início do perfilhamento - estádio 2 da escala de Feeks \& Large (Large 1954). No ano de 2008, cerca de quatro horas após a adubação nitrogenada, foi efetuada irrigação de, aproximadamente, $18,0 \mathrm{~mm}$ e, em 2009, ocorreu precipitação pluvial de 53,0 mm, nove dias após a aplicação dos fertilizantes nitrogenados. Os tratos culturais foram realizados de acordo com as indicações técnicas da Comissão Brasileira de Pesquisa de Trigo e Triticale para o Estado do Paraná (Fronza et al. 2008).

A colheita foi realizada nos dias 02/09/2008 e 16/09/2009, quando a cultura encontrava-se no estádio 11.4, ou seja, no ponto de maturação de colheita (Large 1954), correspondendo a 132 e 139 dias após a emergência das plântulas, em 2008 e 2009, respectivamente. Os grãos colhidos na área útil da parcela foram pesados, para determinação do rendimento de grãos $\left(\mathrm{kg} \mathrm{ha}^{-1}\right)$, com correção para $13 \%$ de umidade. Na mesma época, foi realizada a avaliação de acamamento, estimando-se, visualmente, a percentagem de plantas com inclinação superior a $45^{\circ}$, na área útil da parcela. A altura de plantas foi determinada em três pontos ao acaso, por pacela, considerando-se a medida do nível do solo ao ápice do colmo principal, sem considerar a arista.

A massa de 1.000 grãos foi determinada mediante a pesagem de duas subamostras de 500 grãos de cada parcela e a massa do hectolitro $(\mathrm{MH})$ pela pesagem de uma amostra com volume conhecido (250 mL), obtida no aparelho Dalle Molle ${ }^{\circledR}$, e o resultado transformado na unidade padrão $\left(\mathrm{kg} \mathrm{hL}^{-1}\right)$.

A análise exploratória dos dados foi realizada para verificar o atendimento das pressuposições da análise de variância. As médias de fertilizantes nitrogenados foram comparadas pelo teste Tukey, a 5\%, e os dados de doses submetidos à análise de regressão.

\section{RESULTADOS E DISCUSSÃO}

Durante todo o ciclo da cultura, no ano de 2008, a precipitação foi de $315,0 \mathrm{~mm}$, sendo que, deste total, 141,0 mm ocorreram em 15 dias, durante o enchimento de grãos, e, no ano de 2009 , a precipitação, durante o ciclo, foi de 680,0 mm (Figura 1). Em ambos os anos, as precipitações podem ser consideradas boas, apesar de uma distribuição um pouco 

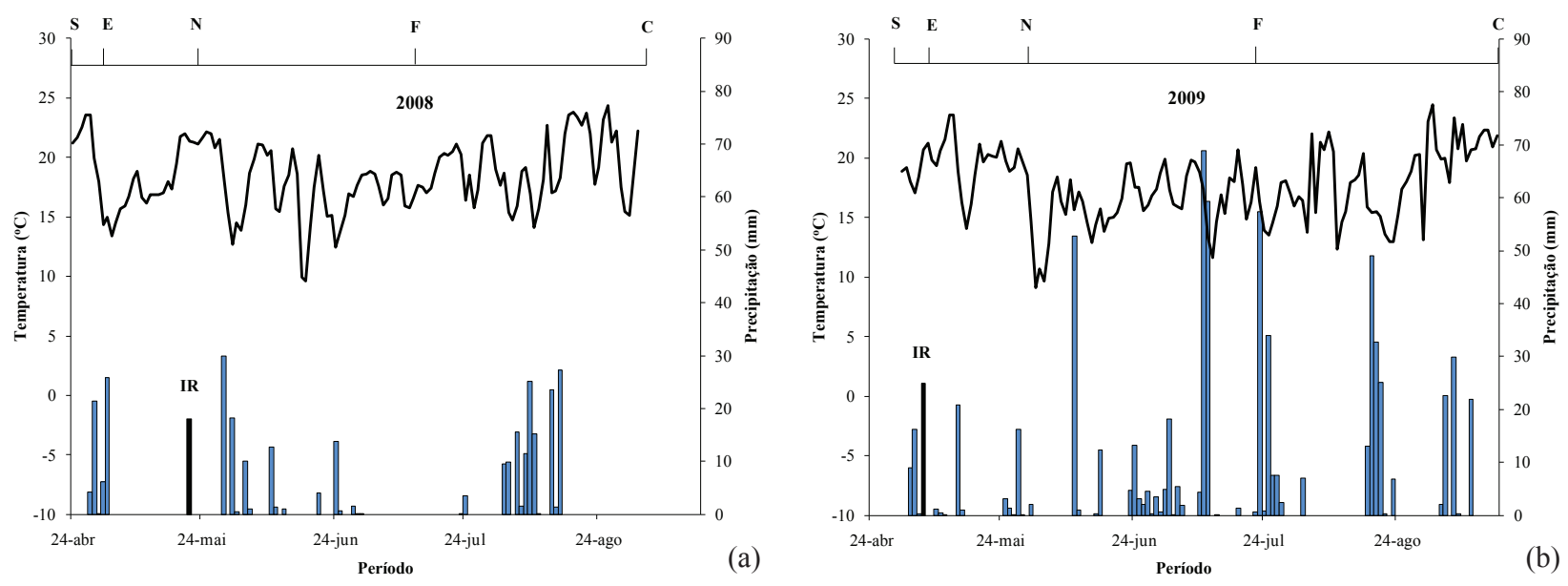

Figura 1. Temperatura média diária $\left({ }^{\circ} \mathrm{C}\right)$ e precipitação $(\mathrm{mm})$, de 24/04/2008 a 02/09/2008 (a) e de 01/05/2009 a 16/09/2009 (b) (Londrina, PR). S: semeadura; E: emergência; N: adubação nitrogenada de cobertura; F: florescimento; C: colheita; IR: Irrigação.

desuniforme em 2008, contudo, em ambos os anos, o bom volume de chuvas, na fase de enchimento de grãos, contribuiu para o acamamento de plantas.

A interação entre doses e fontes de N não foi significativa $(\mathrm{p}<0,05)$ para todas as características avaliadas, nos dois anos de avaliação (2008 e 2009). O incremento nas doses de N não influenciou na altura de plantas, contudo, favoreceu o acamamento (Figura 2). Observou-se, para os dois anos, mais de $80 \%$ das plantas acamadas, na dose de $120,0 \mathrm{~kg} \mathrm{ha}^{-1}$, enquanto, nas parcelas onde não foi aplicado $\mathrm{N}$ em cobertura, observou-se acamamento de $41,6 \%$, no primeiro ano, e 33,3\%, no segundo. Almeida et al. (2002) observaram efeito positivo do N na emissão, desenvolvimento e sobrevivência de perfilhos. Logo, este aumento no acamamento, em função da adubação nitrogenada, deve-se, possivelmente, ao aumento no número de perfilhos e na massa da planta, que podem reduzir a resistência do colmo.

Segundo Fornasieri Filho (2008), o acamamento de plantas de trigo pode ocorrer em maior ou menor intensidade, dependendo do genótipo, que determina a altura de planta, a resistência do colmo e o sistema radicular, sendo influenciado, principalmente, pelas doses de $\mathrm{N}$ e pelo excesso de chuvas, ao final do ciclo da cultura.

O acamamento de plantas ocorreu no estádio 11.2 (grãos no estádio de massa), segundo a escala de Feeks \& Large (Large 1954), respectivamente aos 95 e 88 dias após a emergência das plântulas, em 2008 e 2009, ou seja, correspondendo à fase de enchimento de grãos. O acamamento prejudicou o rendimento de grãos, pois as plantas acamadas receberam menor luminosidade e a translocação da seiva pelo colmo foi prejudicada, reduzindo a massa de 1.000 grãos e, consequentemente, a produtividade (Zagonel \& Fernandes 2007) (Figura 2).

O excesso de chuva, na fase de enchimento de grãos, em 2008, e durante todo o ciclo, em 2009, aliado às condições do solo e à cultivar utilizada, facilitaram o acamamento de plantas. Segundo Zagonel \& Fernandes (2007), uma alternativa para minimizar a ocorrência de acamamento é a utilização de redutores de crescimento que proporcionam diminuição na altura de plantas. A cultivar é classificada como baixa, mas, nas condições deste estudo, a altura das plantas foi de $91,5 \mathrm{~cm}$, no ciclo de 2008, e de 91,9 cm, em 2009. Assim, para esta cultivar, principalmente em anos chuvosos, como observado neste experimento, a utilização de redutores de crescimento é uma estratégia que deve ser considerada.

A produtividade, nas safras 2008 e 2009, foi reduzida a uma taxa negativa de $35 \mathrm{~kg} \mathrm{ha}^{-1}$ e $49 \mathrm{~kg} \mathrm{ha}^{-1}$ de grãos, para cada $10 \mathrm{~kg} \mathrm{ha}^{-1}$ de $\mathrm{N}$ adicionados em cobertura, respectivamente (Figura 2). Logo, em ambos os anos, devido ao acamamento de plantas, a utilização de $\mathrm{N}$ em cobertura, além de aumentar o custo de produção, foi prejudicial ao cultivo do trigo. Estes resultados divergem dos obtidos por Teixeira Filho et al. (2007), que verificaram incremento nas produtividades até a dose de $69 \mathrm{~kg} \mathrm{ha}^{-1}$ de N, por Zagonel et al. (2002), até a dose de $90 \mathrm{~kg} \mathrm{ha}^{-1}$, e Trindade et al. (2006), até a dose de $73 \mathrm{~kg} \mathrm{ha}^{-1}$, porém, os autores obtiveram este desempenho em anos sem a ocorrência de acamamento.

$\mathrm{Na}$ ausência de adubação nitrogenada em cobertura, e somente com a adubação na semeadura, a 

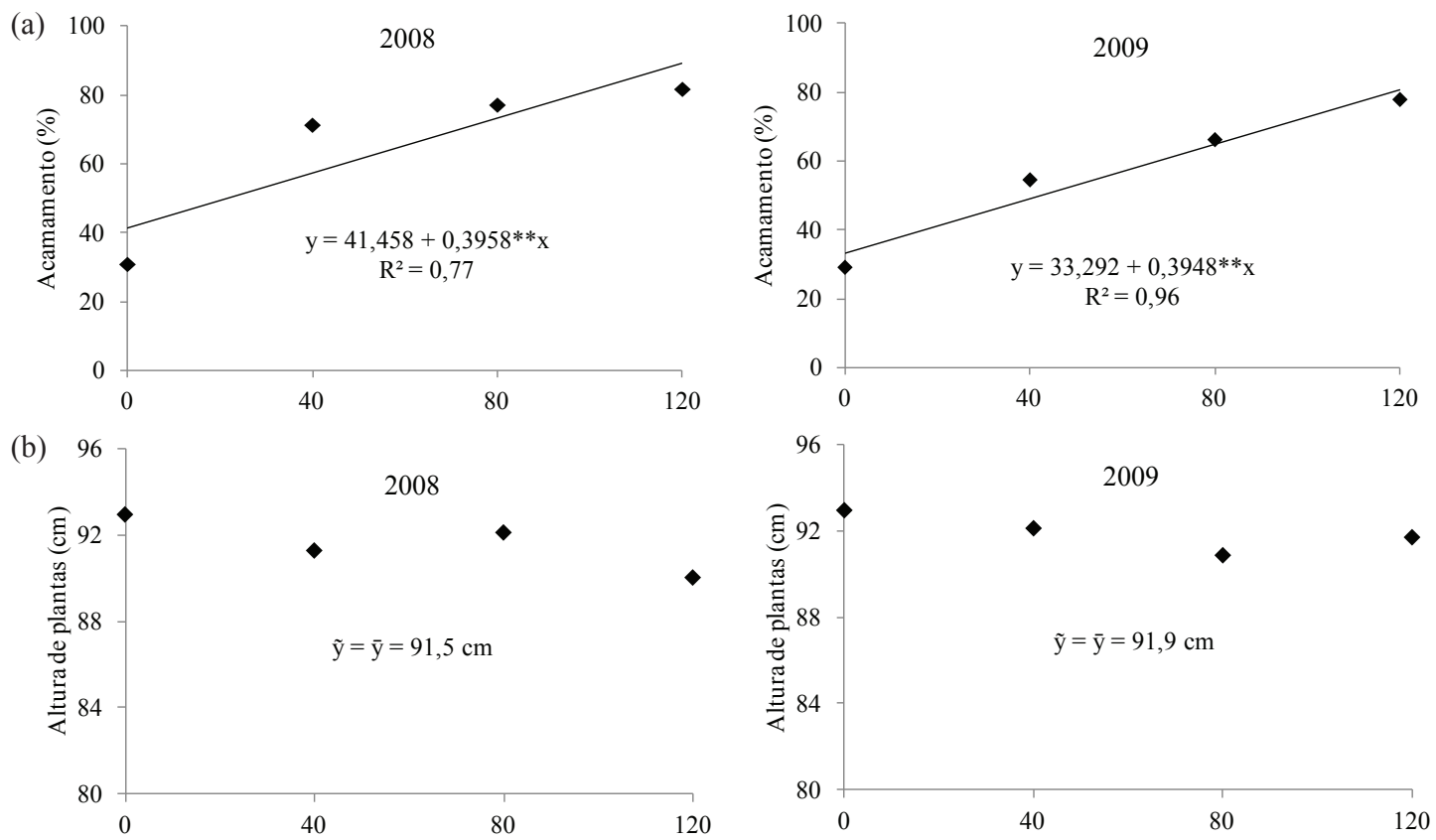

(c)
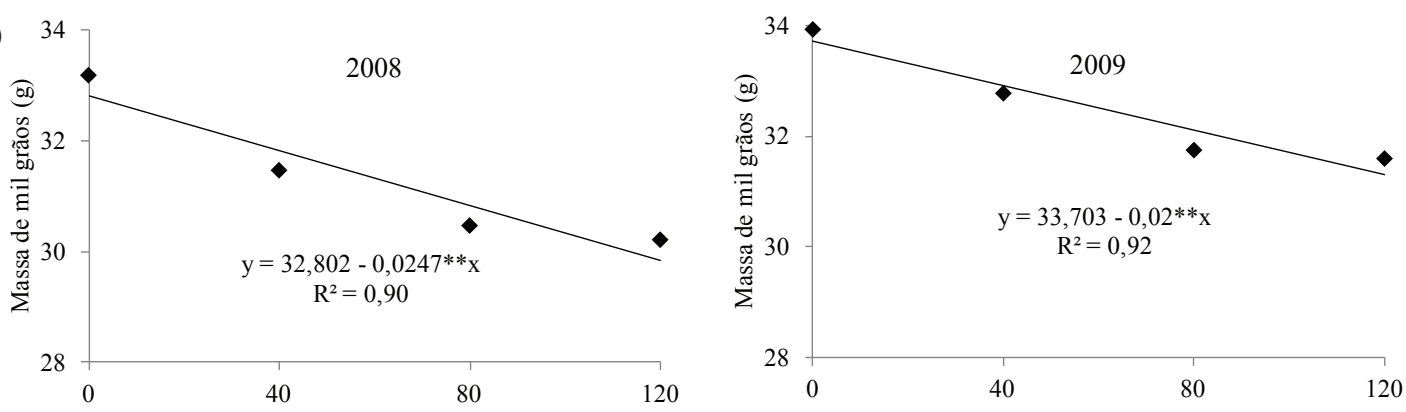

(d)
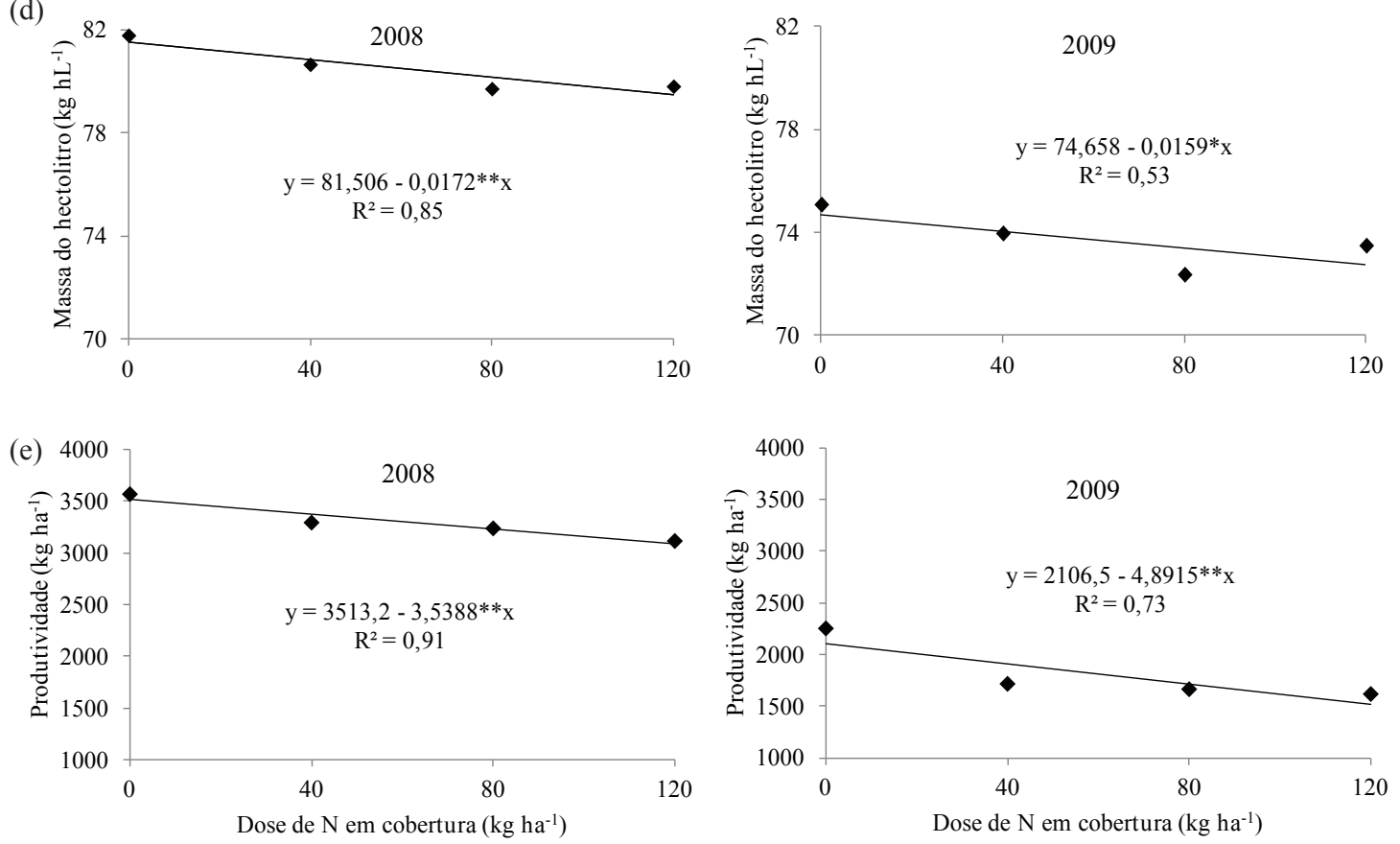

Figura 2. Percentagem de acamamento (a), altura de plantas (b), massa de 1.000 grãos (c), massa do hectolitro (d) e produtividade (e) da cultura do trigo, cultivar BRS Pardela, em função de doses de N aplicadas em cobertura (Londrina, PR, safras 2008 e 2009). ** e * significativo a $5 \%$ e $1 \%$, respectivamente, pelo teste $\mathrm{t}$. 
produtividade foi de, aproximadamente, $3.513 \mathrm{~kg} \mathrm{ha}^{-1} \mathrm{e}$ $2.106 \mathrm{~kg} \mathrm{ha}^{-1}$, respectivamente nas safras 2008 e 2009 (Figura 2). Isto demonstra que grande parte do $\mathrm{N}$ extraído e utilizado pela planta, possivelmente, foi oriundo dos restos culturais da soja e da mineralização da matéria orgânica do solo, e que, nestas condições, doses menores de $\mathrm{N}$ são suficientes para a obtenção de boas produtividades. Prando et al. (2012a), em outra condição edofoclimática, obtiveram produtividade de trigo superior a $4.000 \mathrm{~kg} \mathrm{ha}^{-1}$, sem a aplicação de $\mathrm{N}$ em cobertura, e com apenas $20 \mathrm{~kg} \mathrm{ha}^{-1} \mathrm{de} \mathrm{N}$ na semeadura.

A produtividade média, em 2009, foi $1.488 \mathrm{~kg} \mathrm{ha}^{-1}$ menor que em 2008, devido à ocorrência de brusone, doença que ataca a espiga, principalmente em anos de elevada precipitação no período de florescimento (Tabela 1). A massa do hectolitro (MH) também foi prejudicada, reduzindo-se, em média, $6,8 \mathrm{~kg} \mathrm{hL}^{-1}$. Com isto, a MH, em 2009, passou a fazer parte da classe inferior, tipo 3 (Fronza et al. 2008). Porém, é importante salientar que, mesmo sob esta condição adversa, os resultados obtidos seguiram o mesmo comportamento obtido na safra de 2008, quando a ocorrência de doenças não foi fator limitante para o rendimento de grãos, e o potencial produtivo do experimento foi semelhante ao das lavouras da região de Londrina.

A massa do hectolitro diminuiu, com o incremento nas doses de $\mathrm{N}$, a uma taxa de 0,017 por $\mathrm{kg}$ de $\mathrm{N}$ aplicado em cobertura, no primeiro ano, e 0,016, no segundo ano, ajustando-se a uma equação linear (Figura 2). Este decréscimo está associado à menor massa de 1.000 grãos, ocasionada pelo acamamento, e, também, ao possível aumento no número de grãos por área. Resultados semelhantes foram encontrados por Trindade et al. (2006), Cazetta et al. (2008) e Prando et al. (2012a), que atribuíram a menor massa do hectolitro ao aumento no número de espigas ou grãos por área, fato que aumentou a competição por fotoassimilados, prejudicando o enchimento dos grãos.

No geral, não foi observado efeito das fontes de $\mathrm{N}$ para a maioria das características avaliadas. Apenas no ano de 2008, a ureia proporcionou maior massa do hectolitro que a ureia com inibidor de urease e a ureia revestida, mas esta diferença não se confirmou no ano seguinte. A ausência de resultados divergentes entre as fontes ocorreu nos dois anos, com duas condições pluviométricas diferentes, após a adubação nitrogenada em cobertura. Na safra de 2008, a adubação em cobertura foi realizada com o solo seco, seguida de uma irrigação de, aproximadamente, 18,0 mm. Assim, esta condição é considerada ideal para se obter melhor eficiência do $\mathrm{N}$ aplicado em cobertura, visto que as perdas de $\mathrm{N}$ são mínimas (Malavolta 2006), independentemente da fonte ou forma do fertilizante nitrogenado. Desta maneira, nas condições do estudo, ou seja, com irrigação ou chuvas incorporando os fertilizantes, o fator de escolha é econômico e, neste caso, a ureia é vantajosa, em relação aos outros fertilizantes nitrogenados testados.

Teixeira Filho et al. (2010), avaliando a ureia, o sulfato de amônio e o inibidor de nitrificação (Entec), não observaram diferença entre as fontes, em trigo irrigado, sendo a causa provável da ausência de diferença entre as fontes a irrigação realizada após a aplicação

Tabela 1. Percentagem de acamamento, altura de plantas, massa de 1.000 grãos (MMG), massa do hectolitro (MH) e produtividade da cultura do trigo, cultivar BRS Pardela, em função das fontes de nitrogênio aplicadas em cobertura (Londrina, PR, safras 2008 e 2009).

\begin{tabular}{|c|c|c|c|c|c|}
\hline \multirow{2}{*}{ Fontes de $\mathrm{N}$} & Acamamento & Altura & MMG & MH & Produtividade \\
\hline & $\%$ & $\mathrm{~cm}$ & $\mathrm{~g}$ & $\mathrm{~kg} \mathrm{hL}^{-1}$ & $\mathrm{~kg} \mathrm{ha}^{-1}$ \\
\hline \multicolumn{6}{|c|}{ Safra 2008} \\
\hline Ureia & $62,2 \mathrm{a}$ & $91,6 \mathrm{a}$ & $31,8 \mathrm{a}$ & $81,1 \mathrm{a}$ & $3.295 \mathrm{a}$ \\
\hline Ureia + NBPT & $65,0 \mathrm{a}$ & 91,9 a & $31,1 \mathrm{a}$ & $80,2 \mathrm{~b}$ & $3.250 \mathrm{a}$ \\
\hline Ureia + polímeros & $68,4 \mathrm{a}$ & $91,3 \mathrm{a}$ & $31,1 \mathrm{a}$ & $80,2 \mathrm{~b}$ & $3.357 \mathrm{a}$ \\
\hline Média & 65,2 & 91,6 & 31,3 & 80,5 & 3.301 \\
\hline C.V. (\%) & 30,20 & 3,29 & 2,67 & 1,05 & 5,48 \\
\hline \multicolumn{6}{|c|}{ Safra 2009} \\
\hline Ureia & $57,2 \mathrm{a}$ & $92,8 \mathrm{a}$ & $32,4 \mathrm{a}$ & $73,8 \mathrm{a}$ & $1.822 \mathrm{a}$ \\
\hline Ureia + NBPT & $56,6 \mathrm{a}$ & $92,5 \mathrm{a}$ & $32,5 \mathrm{a}$ & $73,5 \mathrm{a}$ & $1.800 \mathrm{a}$ \\
\hline Sulfato de amônio & $57,2 \mathrm{a}$ & $90,3 \mathrm{a}$ & $32,6 \mathrm{a}$ & $73,8 \mathrm{a}$ & $1.817 \mathrm{a}$ \\
\hline Média & 57,0 & 91,9 & 32,5 & 73,7 & 1.813 \\
\hline C.V. (\%) & 26,69 & 4,44 & 3,53 & 2,87 & 14,51 \\
\hline
\end{tabular}

Médias seguidas por letra diferente, na coluna, diferem entre si, pelo teste Tukey, a $5 \%$. 
do N em cobertura, corroborando Kappes et al. (2009), que não obtiveram diferença em produtividade e outros parâmetros avaliados, em milho safrinha cultivado após a cultura da soja.

$\mathrm{Na}$ safra de 2009, ocorreu precipitação pluvial de 53,0 mm, nove dias após a adubação de cobertura. $\mathrm{O}$ período de nove dias sem precipitação favoreceu a diferença entre as fontes de $\mathrm{N}$, pois ocorreu hidrólise da ureia na superfície e, consequentemente, perdas de $\mathrm{NH}_{3}$ por volatilização. No entanto, mesmo assim, não se observou diferença, pois, provavelmente, esta perda de $\mathrm{N}$ da ureia por volatilização não foi suficiente para resultar em diferenças no desempenho da cultura do trigo.

Pereira et al. (2009), avaliando ureia, ureia + NBPT e ureia revestida com polímeros, na dose de $80 \mathrm{~kg} \mathrm{ha}^{-1} \mathrm{de} \mathrm{N}$, no cultivo de milho safrinha no Cerrado, após a cultura da soja, também não observaram diferenças estatísticas na produtividade, mas constataram que a ureia apresentou maior percentagem de volatilização de amônia, quando comparada à ureia + NBPT e à ureia revestida com polímeros.

Prando et al. (2012a), avaliando as fontes de nitrogênio ureia, ureia + NBPT e ureia revestida, em outra condição climática (clima temperado), não observaram alteração na produtividade, massa de grãos, número de espigas $\mathrm{m}^{-2}$, altura de planta e teor de nitrogênio na folha e no grão. Além disto, Prando et al. (2012b), em trabalho complementar, não constataram efeito significativo na qualidade fisiológica das sementes de trigo.

Pelos resultados obtidos, observaram-se respostas semelhantes, entre as diferentes fontes de $\mathrm{N}$, para todas as características avaliadas. Logo, a ureia se torna a fonte de nitrogênio mais viável, pois apresenta menor custo relativo. Corroborando estes resultados, Yano et al. (2005) também não observaram diferenças nas avaliações realizadas com três fontes de N (ureia, nitrato de amônio e sulfato de amônio). Com isto, a ureia foi a fonte de $\mathrm{N}$ mais vantajosa, assim como observado no presente trabalho.

\section{CONCLUSÕES}

1. O incremento nas doses de $\mathrm{N}$ em cobertura favoreceu o acamamento de plantas da cultivar BRS Pardela, cultivada após a soja, em sistema de semeadura direta, proporcionando redução na massa de 1.000 grãos, massa do hectolitro e produtividade.

2. O sulfato de amônio, a ureia + inibidor de urease (NBPT) e a ureia revestida com polímeros não diferiram da ureia, no desempenho produtivo do trigo cultivado após a cultura da soja e em sistema de semeadura direta.

\section{REFERÊNCIAS}

ALMEIDA, M. L. et al. Cultivares de trigo respondem diferentemente à qualidade da luz quanto à emissão de afilhos e acumulação de massa seca. Ciência Rural, Santa Maria, v. 32, n. 3, p. 377-383, 2002.

CANTARELLA, $\mathrm{H}$. et al. Ammonia volatilization from urease inhibitor-treated urea applied to sugarcane trash blankets. Scientia Agricola, Piracicaba, v. 65, n. 4, p. 397 401, 2008.

CAZETTA, D. A. et al. Qualidade industrial de cultivares de trigo e triticale submetidos à adubação nitrogenada no sistema de plantio direto. Bragantia, Campinas, v. 67, n. 3, p. 741-750, 2008.

FORNASIERI FILHO, D. Manual da cultura do trigo. Jaboticabal: Funep, 2008.

FRONZA, V.; CAMPOS, L. A. C.; RIEDE, C. R. (Orgs.). Informações técnicas para a safra 2008: trigo e triticale. Londrina: Embrapa Soja, 2008. (Documentos, 301).

GOLIK, S. I. et al. Acumulación, removilización, absorción postantesis y eficiencia de utilización de nitrógeno en trigo bajo diferentes labranzas y fertilizaciones. Pesquisa Agropecuária Brasileira, Brasília, DF, v. 38, n. 5, p. 619-626, 2003.

KAPPES, C. et al. Influência do nitrogênio no desempenho produtivo do milho cultivado na segunda safra em sucessão à soja. Pesquisa Agropecuária Tropical, Goiânia, v. 39, n. 3, p. 251-259, 2009.

LARGE, E. C. Growth stages in cereals illustration of the Feeks scales. Plant Pathology, Oxford, v. 4, n. 1, p. 2224, 1954.

MALAVOLTA, E. Manual de nutrição de plantas. São Paulo: Agronômica Ceres, 2006.

PEREIRA, H. S. et al. Ammonia volatilization of urea in the out-of-season corn. Revista Brasileira de Ciência do Solo, Viçosa, v. 33 n. 6, p. 1685-1694, 2009.

PRANDO, A. M. et al. Formas de ureia e doses de nitrogênio em cobertura no desempenho agronômico de genótipos de trigo. Semina: Ciências Agrárias, v. 33, n. 2, p. 621-632, 2012a.

PRANDO, A. M. et al. Formas de ureia e doses de nitrogênio em cobertura na qualidade fisiológica de sementes de trigo. Revista Brasileira de Sementes, Londrina, v. 34 n. 2, p. 272-279, 2012 b.

TEIXEIRA FILHO, M. C. M. et al. Resposta de cultivares de trigo irrigado por aspersão ao nitrogênio em cobertura na região 
do Cerrado. Acta Scientiarum Agronomy, Maringá, v. 29, n. 3 , p. 421-425, 2007.

TEIXEIRA FILHO, M. C. M. et al. Doses, fontes e épocas de aplicação de nitrogênio em trigo irrigado em plantio direto. Pesquisa Agropecuária Brasileira, Brasília, DF, v. 45, n. 8, p. 797-804, 2010.

TRINDADE, M. G. et al. Nitrogênio e água como fatores de produtividade do trigo no Cerrado. Revista Brasileira de Engenharia Agrícola e Ambiental, Campina Grande, v. 10, n. 1, p. 24-29, 2006.

YANO, G. T.; TAKAHASHI, H. T.; WATANABE, T. S. Avaliação de fontes de nitrogênio e épocas de aplicação em cobertura para o cultivo do trigo. Semina: Ciências Agrárias, Londrina, v. 26, n. 2, p. 141-148, 2005.
ZAGONEL, J.; FERNANDES, E. C. Doses e épocas de aplicação de redutor de crescimento afetando cultivares de trigo em duas doses de nitrogênio. Planta Daninha, Viçosa, v. 25 , n. 2, p. 331-339, 2007.

ZAGONEL, J. et al. Doses de nitrogênio e densidade de plantas com e sem um regulador de crescimento afetando o trigo, cultivar OR-1. Ciência Rural, Santa Maria, v. 32, n. 1, p. 25-29, 2002. 